\title{
Factors of Self-Determination to Return after the Long-Term Evacuation Caused by a Nuclear Power Plant Accident
}

\author{
Motoya Yamada1*, Ruruko Kidachi', Mayumi Shimizu² \\ ${ }^{1}$ Graduate School of Health Sciences, Hirosaki University, Hirosaki, Japan \\ ${ }^{2}$ Institute of Radiation Emergency Medicine Hirosaki University, Hirosaki, Japan \\ Email: *yama3010@hirosaki-u.ac.jp
}

How to cite this paper: Yamada, M., Kidachi, R. and Shimizu, M. (2020) Factors of Self-Determination to Return after the Long-Term Evacuation Caused by a Nuclear Power Plant Accident. Open Journal of Nursing, 10, 117-130.

https://doi.org/10.4236/ojn.2020.102007

Received: January 12, 2020

Accepted: February 11, 2020

Published: February 14, 2020

Copyright ( 2020 by author(s) and Scientific Research Publishing Inc. This work is licensed under the Creative Commons Attribution International License (CC BY 4.0).

http://creativecommons.org/licenses/by/4.0/

\begin{abstract}
Aim of the Study: This study aimed to clarify the factors that were relevant to an individual's self-determination to return amidst anxiety after a long-term evacuation due to the Fukushima Daiichi Nuclear Power Plant accident. Method: Semi-structured interviews on whether to return were conducted with nine participants aged 60 - 80 years (eight males and one female) residing in areas where evacuation orders were canceled. The data obtained were analyzed qualitatively and inductively. Result: All participants were returning to their homes. Factors relevant to self-determination to return were represented by five categories: a desire to return 1) emerging from life-experience as a long-term evacuee, 2) retained after obtaining information about the original place of residence, 3 ) acquired from a long-term life as a refugee, 4) retained with the acceptance of the potential risks of returning, and finally 5) people's apprehension over talking about the importance of the future of the younger generation. Discussion: These categories were based on the participants' desire to return and they continued to maintain these thoughts by gathering information and preparing for their return after the long-term evacuation caused by the nuclear accident. It was suggested that the risk perception and the norm in that age group could be among the factors that promoted the choice in maintaining the desire to return.
\end{abstract}

\section{Keywords}

Long-Term Evacuation, Evacuation Instructions Canceled,

Self-Determination to Return, Nuclear Disaster 


\section{Introduction}

As of March 2019, more than 40,000 people were still forced to evacuate the Fukushima Prefecture alone due to the accident at the Tokyo Electric Power Fukushima Daiichi Nuclear Power Station in 2011 [1]. The Fukushima Daiichi nuclear power plant was shut down due to an unexpected tsunami caused by a major earthquake [2], and the cooling function was lost. As a result, a large amount of radioactive material was diffused, and evacuation instructions were extended for a long time in certain areas. Regarding this effect, questionnaire surveys were conducted in 2012 for the Fukushima participants who were living outside the prefecture in 2012, a year after the Great East Japan Earthquake and two years later in 2013 [3] [4]. As a result, in 2013, two years after evacuation, physical changes and changes in the living environment were shown as stressors, leading to prolonged unstable and extraordinary refuge life, and its effect on people's mental health.

The national and local governments have been moving forward with decontamination, infrastructure development and consultation desks [5], and preparations for arranging accommodation for the participants to return [6]. The evacuation order has been gradually lifted from Tamiya City's Miyakoji district three years after the accident. The return rate of the two towns close to the Fukushima Daiichi nuclear power plant whose evacuation orders were canceled after March 2017 is less than $10 \%$ of the population as of December 2018. From this, it can be said that there are not many people who have returned to the affected areas [7] [8]. In the survey of victims' intentions by the Reconstruction Agency (Japanese administrative institution established for a period of time for the purpose of recovery from the Great East Japan Earthquake) FY2016 [9], the reasons for not returning or not being able to make judgments include the premise of return, such as concerns about nuclear power and air dose rates, health-related issues, and the local government's recovery status related to infrastructure development. Those related to future life such as the living infrastructure at the evacuation destination and the educational environment for children are listed. From this result, it can be imagined that the decision regarding the return of evacuees is not easy.

If the evacuation order is canceled in the area that was the base of life before the accident, the evacuees will have three choices to return and rebuild their lives/not return and live in a new place as a base reconstruction/not return as yet (wait for pending decisions). The focus of this study is on how those who have returned to the area where the evacuation order has been lifted are still anxious, and will decide to return. Whichever the evacuees choose, they will stand at a new starting point for rebuilding their lives.

\section{Purpose of Research}

This study aims to clarify the factors relevant to the self-determination of people to return in the presence of various anxiety factors caused by the long-term 
evacuation during the Fukushima Daiichi Nuclear Power Plant accident.

\section{Method}

\subsection{Research Participants}

Participants were nine townspeople residing in the evacuation order cancellation area of J town in Fukushima Prefecture, close to the Fukushima Daiichi nuclear power plant.

\subsection{Data Collection}

\subsubsection{Survey Procedure}

The researcher explained the purpose of the study to the person in charge of radiation health in J town in Fukushima Prefecture and obtained permission to conduct the survey. Participants were required to live in J town and be recommended by the person in charge. When both conditions were met, the researcher contacted the nominated person and investigated.

\subsubsection{Survey Method}

The survey was conducted through a semi-structured interview method. Participants talked freely about what was the important reason for deciding to return to J town. In addition, we recorded information about age, cohabitants before the disaster and at the time of the survey. Conducted at the study participants' homes, each session lasted 40 to 60 minutes. In a survey at home, there were cases where cohabitants were present.

\subsubsection{Data Analysis}

The verbatim record was created from the recording data collected during the interview and was sectioned into one meaningful content. The attendee's opinions were included in the attendee's narrative, considering that the decision to return was the result of a family consultation. The sectioned data were interpreted based on the context of "thoughts and actions when deciding on returning" and then coded. The code was abstracted along with the semantic content similarity and accordingly divided into subcategories and categories. To ensure the appropriateness and validity of the analysis content, the analysis was repeated with the supervision of researchers familiar with qualitative research.

\subsection{Ethics}

This study was conducted with the approval of the ethics committee of the research institution (reference 2016-065). The researcher explained to the participant the research purpose and method, the will of voluntary cooperation and withdrawal, the preservation of anonymity and privacy, the data storage method, and the interview recording permission. Participants' participation was voluntary, and they were asked to notify us if they felt unconformable while sharing their narrative. This is because the research participants suffered from the disaster and experienced a long-term evacuation life, so the possibility of a psycho- 
logical burden caused by recalling past experiences was taken into consideration. The survey was conducted after all the contents related to research cooperation were explained to the participants, and they signed an agreement to participate.

\subsection{Participants Characteristics}

According to the census, the population of town J in Fukushima Prefecture had more than 20,000 townspeople at the time of the 2011 earthquake. In June 2017, three months after the evacuation order was partially lifted, about 400 residents were disclosed.

The overview of the nine participants is shown in Table 1. Participants were aged 60 - 80 years (eight males and one female). All of them were returning to their own homes. Prior to the earthquake, there were nine married couples four with children, one with a child, one with a child and a grandchild. At the time of the survey, there were nine married couples one with a child, and one couple living only on weekends.

\section{Results}

\subsection{Categories of Factors Surrounding Return for Long-Term Evacuees after the Nuclear Accident}

The codes, subcategories, and categories obtained from the participants are shown in Table 2. Hereafter, the word "data" will be written as " ", "code" as [ ], "sub-category" as $<>$, and "category" as [ ]. The narrative of the participants

Table 1. Overview of participants.

\begin{tabular}{|c|c|c|c|c|c|c|}
\hline & \multirow{2}{*}{ Age } & \multirow{2}{*}{ Gender } & \multicolumn{2}{|c|}{$\begin{array}{c}\text { Composition of cohabitants } \\
\text { (number of person (composition)) }\end{array}$} & \multirow{2}{*}{$\begin{array}{l}\text { Clinical characteris- } \\
\text { tics }\end{array}$} & \multirow{2}{*}{$\begin{array}{l}\text { Attendance at the interview } \\
\text { (relationship with particiants) }\end{array}$} \\
\hline & & & before the earthquake & at the time of investigation & & \\
\hline A & late 70’s & Male & $\begin{array}{c}4 \text { people } \\
\text { (couple, son couple) }\end{array}$ & $\begin{array}{l}2 \text { people } \\
\text { (couple) }\end{array}$ & Chronic disease & None \\
\hline B & late 60 's & Male & $\begin{array}{c}3 \text { people } \\
\text { (couple, son) }\end{array}$ & $\begin{array}{c}1 \text { people } \\
\text { (Live with spouse on weekends) }\end{array}$ & Prostate disease & None \\
\hline $\mathrm{C}$ & late 80 's & Male & $\begin{array}{c}7 \text { people } \\
\text { (couple, son couple, grandchild) }\end{array}$ & $\begin{array}{l}2 \text { people } \\
\text { (couple) }\end{array}$ & Chronic disease & None \\
\hline $\mathrm{D}$ & early 70's & Male & $\begin{array}{c}3 \text { people } \\
\text { (couple, son) }\end{array}$ & $\begin{array}{l}2 \text { people } \\
\text { (couple) }\end{array}$ & Chronic disease & None \\
\hline $\mathrm{E}$ & late 70’s & Male & $\begin{array}{c}3 \text { people } \\
\text { (couple, son) }\end{array}$ & $\begin{array}{l}2 \text { people } \\
\text { (couple) }\end{array}$ & Chronic disease & Spouse \\
\hline $\mathrm{F}$ & early 60's & Male & $\begin{array}{c}3 \text { people } \\
\text { (couple, daughter) }\end{array}$ & $\begin{array}{l}2 \text { people } \\
\text { (couple) }\end{array}$ & Heart disease & Spouse \\
\hline G & late 70’s & Female & $\begin{array}{l}2 \text { people } \\
\text { (couple) }\end{array}$ & $\begin{array}{l}2 \text { people } \\
\text { (couple) }\end{array}$ & Unknown & None \\
\hline $\mathrm{H}$ & early 70's & Male & $\begin{array}{l}2 \text { people } \\
\text { (couple) }\end{array}$ & $\begin{array}{l}2 \text { people } \\
\text { (couple) }\end{array}$ & $\begin{array}{l}\text { Chronic disease, } \\
\text { cerebral infarction }\end{array}$ & Spouse \\
\hline I & late 70’s & Male & $\begin{array}{l}2 \text { people } \\
\text { (couple) }\end{array}$ & $\begin{array}{c}3 \text { people } \\
\text { (couple, daughter) }\end{array}$ & Unknown & Spouse \\
\hline
\end{tabular}


Table 2. Categories of factors surrounding return for long-term evacuees after the nuclear power plant accident.

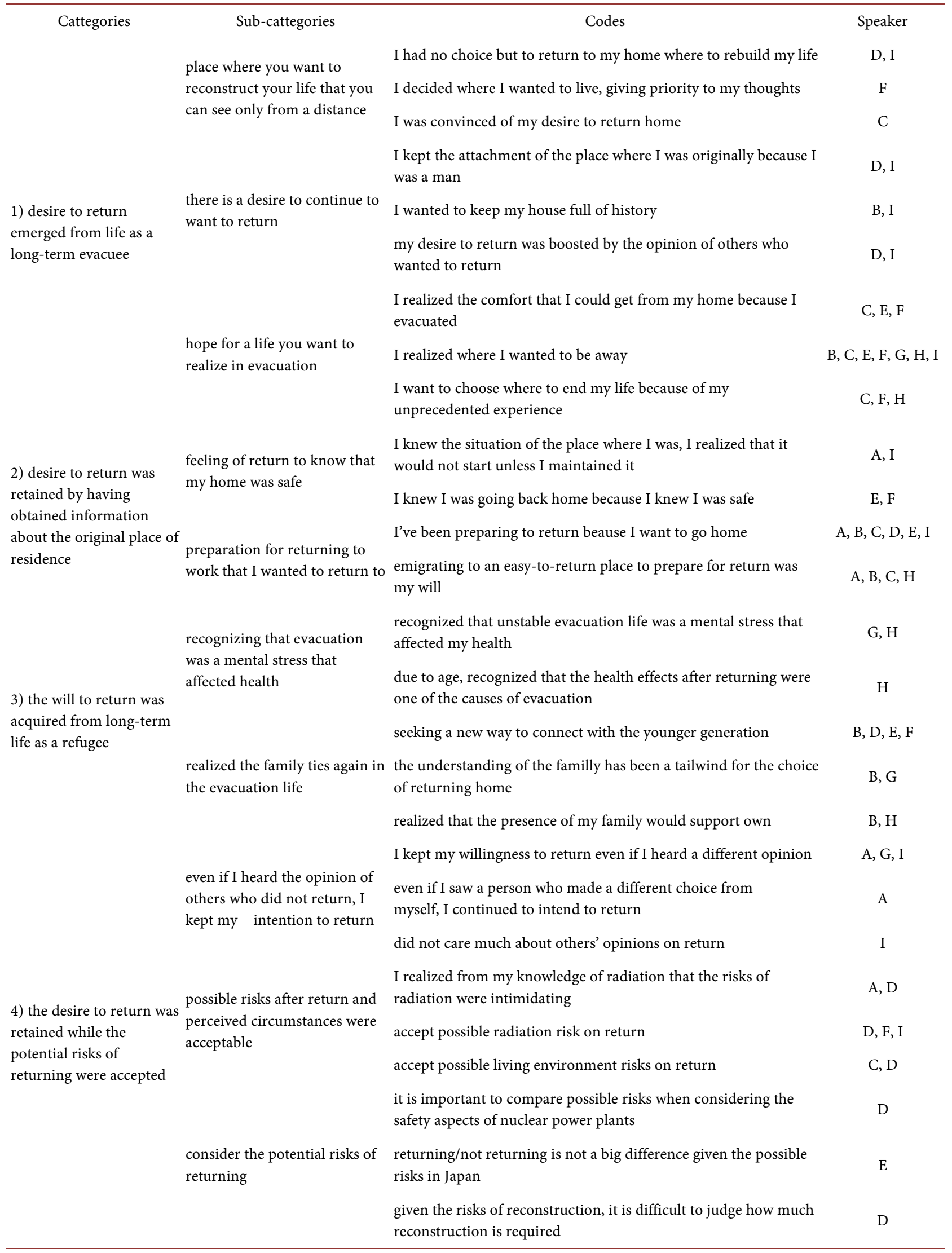




\section{Continued}

\begin{tabular}{|c|c|c|c|}
\hline \multirow{5}{*}{$\begin{array}{l}\text { 5) people's apprehension } \\
\text { over talking about the } \\
\text { importance of the future } \\
\text { of the younger generation }\end{array}$} & & $\begin{array}{l}\text { the choice of the younger generation for the future is } \\
\text { entrusted it to the person in question }\end{array}$ & $\mathrm{F}, \mathrm{G}, \mathrm{H}$ \\
\hline & $\begin{array}{l}\text { watching the future of the } \\
\text { young generation not living } \\
\text { together }\end{array}$ & $\begin{array}{l}\text { considering the living base of the evacuation destination of the } \\
\text { young generation, the option of not returning is } \\
\text { understandable }\end{array}$ & E, F, H \\
\hline & & $\begin{array}{l}\text { the decision of the young generation is entrusted it to the person } \\
\text { in question considering the risk of radiation }\end{array}$ & $\mathrm{D}, \mathrm{I}$ \\
\hline & $\begin{array}{l}\text { thinking about future choices } \\
\text { for young people who are not }\end{array}$ & $\begin{array}{l}\text { after returning home, feel the prospect of living with the young } \\
\text { generation }\end{array}$ & $\mathrm{A}, \mathrm{F}$ \\
\hline & living together & $\begin{array}{l}\text { even after returning, thinking about the future for the young } \\
\text { generation }\end{array}$ & $\mathrm{G}, \mathrm{H}$ \\
\hline
\end{tabular}

comprised records of 140 data, 32 codes, 12 sub-categories, and 5 categories. Factors relevant to self-determination to return were represented by five categories. There were two categories that led to the factors that self-determination return significantly: Category 1) [desire to return emerged from life as a long-term evacuee], Category 2) [desire to return was retained by having obtained information about the original place of residence]. There were two categories that led to the factors that continued to maintain the desire to return: Category 3) [the will to return was acquired from long-term life as a refugee], Category 4) [the desire to return was retained while the potential risks of returning were accepted]. There was one category indicated that the decision to return was not just about the individual: Category 5) [people's apprehension over talking about the importance of the future of the younger generation].

\subsection{Category 1) Desire to Return Emerged from Life as a Long-Term Evacuee}

Category 1) included <place where you want to reconstruct your life so that you can see only from a distance $><$ there is a desire to continue to want to return $>$ $<$ hope for a life you want to realize in evacuation $>$ and was derived from eight people. $<$ There is a desire to continue to want to return $>$ was derived from two codes such as [I kept the attachment of the place where I was originally because I was a man] [I wanted to keep my house full of history]. These were included in the narratives about the survival of home and his fulfillment as the head of the family.

"It's hard to imagine ending here on my behalf. $(B)$ "

"I think the word is that I want to go back to making a place where I live and building a castle in that place. (D)"

This included that the tangible property that I built up and the heart of my hometown were different from the dimension that I settled with compensation. The property also included content that urges researchers who are third parties to be tired of being unable to return to their homes even though they existed after evacuation. 
"I have compensation, but it's not money. I have my own home and my hometown, but when I get back there, I was told I wasn't worried. (omitted) I didn't think it was so hard that I couldn't go home where I had my property. (C)"

In this way, Category 1 was a collection of contents that would continue to ask why the participants wanted to return, confirm, and make sure reasons.

\subsection{Category 2) Desire to Return Was Retained by Having Obtained Information about the Original Place of Residence}

Category 2) included two sub-categories: <feeling of return to know that my home was safe $>$ and $<$ preparation for returning to work that I wanted to return to $>$. These were derived from eight people.

$<$ feeling of return to know that my home was safe $>$ was derived from two codes, such as [I knew the situation of the place where I was, I realized that it would not start unless I maintained it]. This subcategory was included in the narratives that knew what was going on in their homes and which prepared them to return home.

"My house is very rough, so I thought I had to go to the house and do some cleanup. $(A)$ ”

$<$ preparation for returning to work that I wanted to return to $>$ was derived from two codes, such as [I've been preparing to return because I want to go home]. This subcategory was included in the narratives that it was different from my house before the earthquake, but I knew that I was able to prepare while maintaining my desire to return, and frequently returned to my house to proceed with preparations.

"At first, the grass was so stretched and it was really hard to get into the house. I cut the hard grass little by little. (omitted) I never didn't feel like I couldn't go home. (A)"

"At first, I didn't go home every day, but when I realized I went home every day. $(H)$ "

As described above, category 2 summarizes the content that strengthens the desire to return by collecting information on the return destination.

\subsection{Category 3) the Will to Return Was Acquired from Long-Term Life as a Refugee}

Category 3) included two sub-categories: <recognizing that evacuation was a mental stress that affected health $><$ realized the family ties again in the evacuation life $>$. These were derived from six people.

$<$ recognizing that evacuation was a mental stress that affected health $>$ was derived from two codes, such as [recognized that unstable evacuation life was a mental stress that affected my health].

"The people around were full of strangers at the evacuation site. The people who lived evacuated apart. (omitted) $P$ ve been going home at first, and 1 ve experienced that people who said they' re going home are getting sick. (G)" 
$<$ realized the family ties again in the evacuation life $>$ was derived from three codes, such as [the understanding of the family has been a tailwind for the choice of returning home]. This sub-category was included in the data that boosted the families who decided to return.

"I thought I had to go home again because my wife was in tune. (D)"

As described above, Category 3 summarized the changes that were felt during the evacuation life, which supported their desire to return.

\subsection{Category 4) the Desire to Return Was Retained While the Potential Risks of Returning Were Accepted}

Category 4) included three sub-categories: <even if I heard the opinion of others who did not return, I kept my intention to return $><$ possible risks after return and perceived circumstances were acceptable $>$ and $<$ consider the potential risks of returning $>$. These were derived from eight people.

$<$ even if I heard the opinion of others who did not return, I kept my intention to return $>$ was derived from three codes, such as [I kept my willingness to return even if I heard a different opinion]. In this subcategory, the different opinions and actions of others did not interrupt their desire to return.

"Even if my friend didn't go home, I thought I was decided to return. (I)"

$<$ possible risks after return and perceived circumstances were acceptable $>$ was derived from three codes, such as [I realized from my knowledge of radiation that the risks of radiation were intimidating]. There were two types of risks that could arise from return. One was related to nuclear power and radiation, and the other was related to the living environment after returning. These risks described what they had endured on returning.

"It's not a big deal in the year, it's okay. $(A)$ "

"P $m$ back because $P m$ prepared for inconvenience and anxiety. $(D)$ "

$<$ consider the potential risks of returning $>$ was derived from three codes, such as [it is important to compare possible risks when considering the safety aspects of nuclear power plants] [Returning/not returning is not a big difference given the possible disaster risks in Japan]. This sub-category was included in the data where the potential risks of returning were traded off by considering other risks.

"Even if you are in the mountains, the mountains will explode. It is the same everywhere. (E)"

In this way, Category 4) consolidates the content of reconciliation by facing the risks that may return.

\subsection{Category 5) People Were Apprehensive to Talk about the Importance of Future of the Younger Generation}

Category 5) included two sub-categories: <watching the future of the young generation not living together $>$ and $<$ thinking about future choices for young people who are not living together $>$. These were derived from eight people. This subcategory included narratives about the physical changes during the evacuation that were influenced by mental stress from evacuation life, especially about 
interpersonal stress when no one is around.

$<$ watching the future of the young generation not living together $>$ was derived from three codes, such as [Young generations leave their choices for the future to themselves]. <thinking about future choices for young people who are not living together> was derived from two codes, such as [After returning home, feel the prospect of living with the younger generation]. This category included content that respected the will of the younger generation who once lived with them.

"I think the best thing I can do now is if I do what I like for my child. $(F)$ "

"I thought I had to talk (about returning) soon (to the child). (H)"

\section{Discussion}

\subsection{The Relationship between the Category of Factors That Determine Return and the Passage of Time}

The extracted categories were considered to be positioned after the Fukushima Daiichi accident. This was not merely a lapse of time, but evacuees were involved in changes in social conditions, including policies until the evacuation order was lifted, and reluctantly built a prolonged evacuation life. It is thought that the result was that the evacuees had been willing to return while swaying in various information. Figure 1 shows the relationship between the categories of factors that determine the return and the passage of time. The time from the $2011 \mathrm{Fu}$ kushima Daiichi accident to 2017 at the time of the survey was plotted on the horizontal axis. In the upper row, the situation of the Fukushima Daiichi Nuclear Power Plant, the situation of the town, the social situation such as changes

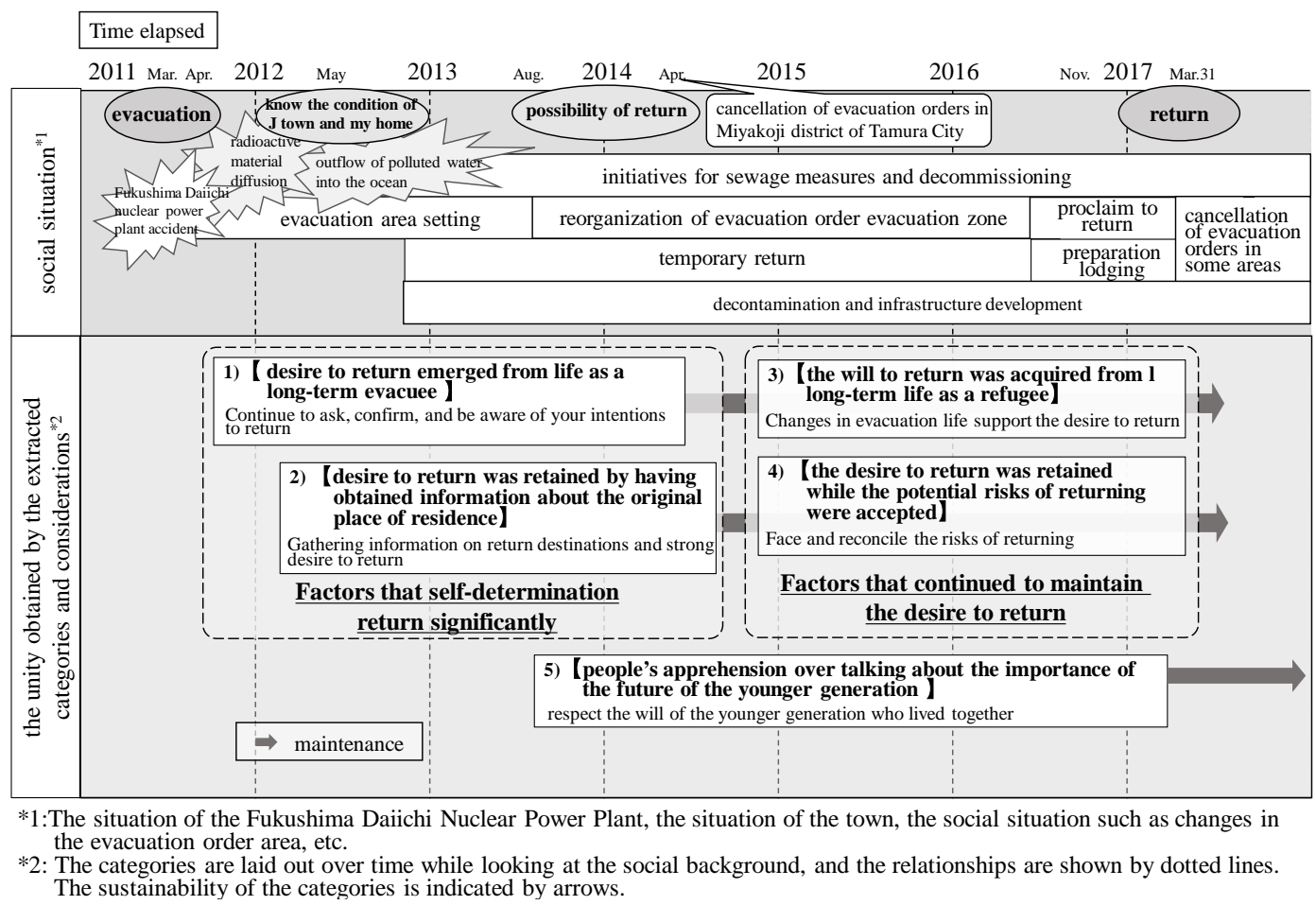

Figure 1. Relationship between the category of factors that determine return and the passage of time. 
in the evacuation order area, and the categories in the middle row, and the sustainability is indicated by arrows.

The residents who were evacuated due to the Fukushima Daiichi nuclear accident lost their livelihoods and became unstable in terms of their lives and mental health. The uncertain situation of the Fukushima Daiichi Nuclear Power Plant and the intricate information on the town, which were reported every day, prolonged the situation where they could not return. Category 1) [desire to return emerged from life as a long-term evacuee] was positioned in such an evacuation life. Then, when it was time to start returning home or review the transition of the area, it became possible to collect information on return destinations. It was thought that this would lead to Category 2) [desire to return was retained by having obtained information about the original place of residence] which strengthened the feeling of return.

However, if the evacuation order is canceled slowly, it will be difficult to retain the intention. Regarding the factors supporting Category 1) and 2), the change in evacuation life supports the willingness to return in Category 3) [the will to return was acquired from long-term life as a refugee], and the category 4) [the desire to return was retained while the potential risks of returning were accepted] that confronts the risks of returning was positioned.

In category 5) [people were apprehensive about the importance of the future of the younger generation], it is difficult to identify the time, but the evacuation triggered the younger generation to live apart from the evacuation destination, so the next time they came back home, it was thought that they would accept themselves to watch over, separated from the life created by generational families.

\subsection{Reasons for Wanting to Return from the Norm Where Priority Was Given}

Participants' willingness to return could be considered a strong reason for returning. In considering the reasons, we also consider the influence of pre-war or domestic tradition norms, considering the age of participants.

It is said that nostalgia is prone to occur in negative emotional states such as loneliness and depression, and it is said that the feeling nostalgia increases positive emotions [10]. Looking at Category 1) [desire to return emerged from life as a long-term evacuee], it was thought that nostalgia, which is a longing for the past, was involved. participants would have been more likely to cause nostalgia because they had evacuated and left their homeland. It can be imagined that those who were forced to leave their hometown became more aware of the "goodness" of the town where they once lived.

In the same category <there is a desire to continue to want to return> was contained in expressions that seemed to be a remnant of the home system, such as "duty to protect tombs," "for generations," "do not be unfortunate," and "graves, houses, and property." This was thought to be related to the family sys- 
tem that continued in Japan for about 50 years after the enforcement of the Civil Code in 1898. The house system is a system in which, among persons with relatives, a narrower range of people belong to one house as head of the family, and the head has authority over the house [11]. Under the house system, it was stipulated that the owner of the house should take over the house, that the continuation of the house and the service of the ancestors be given priority, and that the grave be protected. Although the form itself has collapsed due to the declining birthrate and the progress of nuclear families, it is said that even after the abolition of the system, ideas remain in the consciousness of people [12]. At the age of participants, the tradition of having to return and play a role that they should have played was considered to have been one of the factors that permeated their willingness to return.

\subsection{Reasons for Wanting to Return from the Norm Where Priority Was Given}

Retention of willingness to return was Category 3) [the will to return was acquired from long-term life as a refugee] and Category 4) [the desire to return was retained while the potential risks of returning were accepted].

Category 3), $<$ Recognition that evacuation life was mental stress that affected health $>$ was thought to have encouraged the desire to return to escape or eliminate stressful evacuation life. According to Category 3, < renewed Family Bonds in Evacuation Life>, agreement with the family was important in deciding to return. It is probable that the family helped them to return home, as in "I came home after talking with my son" and "I came home because my wife was OK."

The risks of Category 4) [the desire to return was retained while the potential risks of returning were accepted] were related to the safety aspects of nuclear power and radiation, and the environmental aspects of living. The risk corresponding to this is the above-mentioned illness caused by stress when continuing evacuation. participants have come to terms with these statements-"Be prepared," "Because $1 m$ old," " $m m$ fine at this level," and " $P m$ not worried"-about the risks of returning. That is, it is considered a trade-off to reduce the severity of the risk by considering the degree of the risk, not the presence or absence of the risk [13]. After gathering information on the risks and confirming them while checking them on the ground, if the desire to return was strong, it was a factor that boosted the desire to return by making light of safety risks. This confirms that the method of weighting the risk depends to some extent on the will to achieve. These suggest that it is important to confirm each motivation and to support factors that make return decision making difficult.

\subsection{The Relationship between Next-Generation Families and Decision-Making Factors for Returning}

Category 5) [people were apprehensive to talk about the importance of the future of the younger generation] was that the returning people could be sup- 
ported by their families and retain their intention to return, at the same time, care for the younger generation and boost their life. This was believed to have been performed by the repatriated side of the elderly.

Among the reasons why the results of the Reconstruction Agency's survey of residents' intentions [9] did not return, respondents who said they already had a living foundation or wanted to continue education for their children in the current environment were those who were raising children or working. In such cases, we consider the expression "don't talk."

However, because of the parent's position and the existence of children and grandchildren, consideration for important others backed by bonds may be made. For those who are in the elder or retirement stage of the family development stage [14], the elderly said, "Let's call," or " $P m$ doing what I like now." It is thought that watching over was an action that encouraged the independent younger generation to choose their life. This is because the younger generation is living apart from themselves, rebuilding their lives on the land, like "building a house and living" and "going elsewhere." It was supported by what I had confirmed.

\section{Conclusions}

From the narratives of nine people who returned to town A in Fukushima Prefecture where evacuation orders were lifted after a long-term evacuation after the Fukushima Daiichi nuclear power plant accident, the following categories were extracted as factors that determine the return. Category 1) desire to return emerged from life as a long-term evacuee, Category 2) desire to return was retained by having obtained information about the original place of residence, Category 3) the will to return was acquired from long-term life as a refugee, Category 4) the desire to return was retained while the potential risks of returning were accepted], and Category 5) people's apprehension over talking about the importance of the future of the younger generation.

These categories were considered to be positioned over time after the accident. Categories 1) and 2) confirmed their wishes because of the lack of their previous lives due to forced evacuation and continued to collect and prepare information for their return. Categories 3) and 4) were factors that supported the desire to return for a long time before they could return. Category 5) was considered to be a factor in accepting to be on the watch side of the younger generation's life, although it is difficult to determine when. It was suggested that the reason for the desire to return was that the norms in the age of co-workers and the way of perceiving risk also helped the choice.

\section{Acknowledgements}

We would like to thank the residents of J Town in Fukushima Prefecture for their time and cooperation with this research. I would also like to express my sincere appreciation to the staff in J Town, Fukushima Prefecture for their con- 
sent to conduct the research and for recommending their collaborators.

This research is part of a master's thesis in graduate school. Part of this research was presented at the 9th International Conference on High-Level Environmental Radiation Areas.

\section{Conflicts of Interest}

The authors declare no conflicts of interest regarding the publication of this paper.

\section{References}

[1] Fukushima Disaster Response Headquarters (2019) Immediate Report on Damage Caused by the Tohoku-Pacific Ocean Earthquake 2011. https://www.pref.fukushima.lg.jp/uploaded/life/460741 1172968 misc.pdf

[2] TEPCO Holdings (2019) Outline of Fukushima Daiichi Nuclear Power Plant Accident. http://www.tepco.co.jp/nu/fukushima-np/review/review1_1-j.html

[3] Maya, Y., Takuya, T., Kazutaka, M., Takahiro, I., Noriko, I., Chikako, F., Shuzo, H., Tadashi, I., Koichi, N., Takaya, K., Atsushi, O. and Hiroaki, K. (2016) Social Factors Affecting Psychological Stress of the Evacuees out of Fukushima Prefecture by the Cause of Nuclear Accident after the Great East Japan Earthquake. Japanese Journal of Psychosomatic Medicine, 56, 819-832.

[4] Takuya, T., Kumiko, K., Takahiro, I., Kazutaka, M., Maya, Y., Chikako, F., Noriko, I., Ryuhei, M., Takaya, K., Koichi, N., Atsushi, O. and Hiroaki, K. (2016) High-Level Post-Traumatic Stress Symptoms of the Residents in Fukushima Temporary Housing. Japanese Journal of Psychosomatic Medicine, 56, 724-736.

[5] Cabinet Office Life Support Team for Nuclear Victims (2018) About the Situation of the Evacuation Order Area.

http://www.mext.go.jp/b menu/shingi/chousa/kaihatu/016/shiryo/ icsFiles/afieldf ile/2018/08/10/1408009 03 1.pdf

[6] Fukushima Reconstruction Station (2019) Commerce/Tourism/Tokyo Olympics/Paralympics. http://www.pref.fukushima.lg.jp/site/portal/list278.html

[7] Tomioka Town (2018) Number of People Evacuating and Living inside and outside the Prefecture. http://www.tomioka-town.jp/soshiki/jumin/jumin/oshirase/2153.html

[8] Namie Town (2019) Namie Reconstruction Report. https://www.town.namie.fukushima.jp/uploaded/attachment/9858.pdf

[9] Reconstruction Agency (2016) Report on the Survey of Resident Intentions Due to Nuclear Disasters. http://www.reconstruction.go.jp/topics/main-cat1/sub-cat1-4/ikoucyousa/28ikouch ousakekka zentai.pdf

[10] Wildschut, T., Sedikides, C., Arndt, J. and Routledge, C. (2006) Nostalgia. Journal of Personality and Social Psychology, 91, 975-993. https://doi.org/10.1037/0022-3514.91.5.975

[11] Sakae, W. (2015) Civil Code Guide. Signpost of Private Law, Keisoshobo, Tokyo.

[12] Hiromi, S. (2015) The Mixture of Law and Trial over the Family Style: What the Family Ought to Be. The Bulletin of the Junior College Division of Kinki University, 48, 23-42. https://kindai.repo.nii.ac.jp/?action=repository uri\&item id=10780\&file id=40\&fil 
$\underline{\text { e no }=1}$

[13] Katsuhiko, T. (2012) Biases in Risk Perception: Why Risks Are Underestimated. Organizational Science, 45, 55-65.

https://www.aaos.or.jp/contents/committee/file/045-4-6.pdf

[14] Kiyomi, M. and Takashi, M. (1998) New Family Sociology, Baifukan, Tokyo. 